\title{
EARLY EXPERIENCE WITH MINIMALLY INVASIVE DIRECT CORONARY ARTERY BYPASS GRAFTING WITH THE INTERNAL THORACIC ARTERY
}

John R. Doty, MD

James D. Fonger, MD

Jorge D. Salazar, MD

Peter L. Walinsky, MD

Neal W. Salomon, MD
Objective: Minimally invasive direct coronary artery bypass is performed under direct vision without sternotomy or cardiopulmonary bypass. The technique can be used in both primary and reoperative cases by employing the internal thoracic artery to perform arterial revascularization of the anterior surface of the heart. Methods: Patients were selected who had significant coronary artery disease limited to 1 or 2 coronary distributions on the anterior surface of the heart. Coronary target vessels were grafted with the internal thoracic artery through a small anterior thoracotomy. After partial heparinization the anastomosis was facilitated by local coronary occlusion and handheld stabilization. Results: Between August 1994 and July 1997, 162 patients underwent minimally invasive direct coronary artery bypass grafting with the internal thoracic artery. The left and right internal thoracic arteries were used for grafting of the left anterior descending artery in 142 patients $(88 \%)$, the proximal right coronary artery in 7 patients $(4 \%)$, existing saphenous vein grafts in 5 patients $(3 \%)$, and diagonal branches in 2 patients $(1 \%)$. Sequential grafting with the left internal thoracic artery was performed in 2 patients $(1 \%)$ and bilateral internal thoracic artery grafting was performed in 4 patients $(3 \%)$. Eight patients $(4.9 \%)$ died within 30 days after the operation, 3 of cardiac causes. Seven additional patients died during the follow-up period. Nine patients $(5.6 \%)$ required reintervention for graft stenosis or occlusion during follow-up. Of 141 patients seen 2 or more weeks after the operation, $135(96 \%)$ had resolution of their anginal symptoms at a mean follow-up of 12 months (range 0-31 months). Conclusions: Anterior minimally invasive direct coronary artery bypass grafting with the internal thoracic artery avoids the risks of repeated sternotomy, aortic manipulation, and cardiopulmonary bypass. There was a low rate of reintervention, and patients had excellent resolution of anginal symptoms. Postoperative length of stay was comparatively short, and continued follow-up will be essential to evaluate long-term graft patency and patient survival. (J Thorac Cardiovasc Surg 1999;117:873-80)
$\mathrm{M}$ inimally invasive direct coronary artery bypass (MIDCAB) grafting is being used in an increasingly wider range of patients as operative techniques

From the Divisions of Cardiac Surgery, Sinai Hospital at Baltimore and Washington Adventist Hospital, Takoma Park, Md.

Received for publication May 14, 1998; revisions requested July 13, 1998; revisions received Dec 23, 1998; accepted for publication Dec 30, 1998.

Address for reprints: James D. Fonger, MD, Adventist Heart, 7610 Carroll Ave, Suite 440, Washington Adventist Hospital, Takoma Park, MD 20912.

Copyright (C) 1999 by Mosby, Inc.

$0022-5223 / 99 \$ 8.00+0 \quad \mathbf{1 2 / 1 / 9 6 8 5 1}$ and instrumentation continue to evolve. The various techniques developed for MIDCAB surgery now allow grafting of all coronary distributions in patients who need either primary or reoperative procedures. Early experiences have been reported by several authors. ${ }^{1-4}$

MIDCAB techniques were developed in an effort to avoid some of the potential complications of conventional coronary artery bypass grafting by using smaller incisions, eliminating cardiopulmonary bypass, avoiding manipulation of the great vessels or of existing grafts, and using arterial conduits. Repeated sternotomy in particular has inherent risks, including injury to patent grafts, the heart, and great vessels; embolization 
Table I. Patient demographics $(n=162)$

\begin{tabular}{lrr}
\hline & No. & $\%$ \\
\hline Risk factors & & \\
Age (y) & & \\
$\quad$ Mean & 63.8 & \\
$\quad$ Range & $35-89$ & 46.3 \\
Age >65 y & 75 & 60.5 \\
Male gender & 98 & 68.5 \\
Hypertension & 111 & 29.0 \\
Diabetes mellitus & 47 & 6.2 \\
Carotid bruit & 10 & 8.6 \\
Previous cerebrovascular accident & 14 & 90.7 \\
Indications for operation & & 17.9 \\
Angina & 147 & 48.8 \\
Dyspnea & 29 & 11.1 \\
Positive thallium stress test result & 79 & \\
Preoperative myocardial infarction & 18 & 36.4 \\
Preoperative catheter-based interventions & & 12.3 \\
Percutaneous transluminal angioplasty & 59 & 3.1 \\
Stent & 20 & 6.8 \\
Rotational ablation & 5 & \\
Atherectomy & 11 & \\
Any intervention & 62 & \\
\hline
\end{tabular}

of atherosclerotic debris from the aorta or diseased vein grafts; and subsequent wound complications. Conventional coronary artery bypass grafting in reoperative cases is associated with both prolonged cardiopulmonary bypass and increased operative times as a result of more extensive dissection.

This experience demonstrates that minimally invasive techniques that use the internal thoracic artery (ITA) can result in favorable early patient outcomes, reduce some of the morbidity associated with conventional coronary artery bypass grafting, and result in a more rapid recovery after the operation. Long-term outcomes, however, are necessary for a full evaluation of the value of the MIDCAB approach.

\section{Patients and methods}

Patient selection. Patients were selected in a consecutive manner for revascularization with MIDCAB grafting of the ITA if they had significant coronary artery stenosis $(>50 \%$ angiographically determined narrowing) limited to 1 or 2 coronary distributions on the anterior surface of the heart. All patients had symptoms refractory to medical therapy, including catheter-based interventions. Exclusion criteria for the MIDCAB approach included the presence of significant coronary disease in more than 2 coronary distributions and active myocardial ischemia necessitating intravenous nitrate administration or mechanical support. Patients were not excluded on the basis of age, weight, functional status, presence of functional grafts to other areas of the heart, or other preoperative risk factors, such as previous stroke, previous myocar- dial infarction, or impaired pulmonary or renal function. Preoperative demographic data are summarized in Table I.

Operative technique. The patients were prepared for the MIDCAB operation as for a conventional cardiac operation, including placement of central venous access, an arterial pressure monitor, and a urinary drainage catheter. The anterior portion of the chest was prepared and draped as for a conventional cardiac operation, with extended lateral draping on the side intended for grafting to allow for the small anterolateral thoracotomy.

An 8-cm transverse skin incision was made at the level of the fourth costal cartilage, just lateral to the sternal border. In male patients the incision was located above the nipple; in female patients the incision was placed just above the submammary fold. The fourth cartilage was released just lateral to the ITA and reflected inferiorly, or removed in early cases. Exposure was optimized by means of a conventional retraction system (Rultract, Inc, Cleveland, Ohio) to simultaneously elevate the third cartilage and the sternal table. The ITA was dissected off the chest wall and skeletonized from the undersurfaces of the first through fifth costal cartilages to ensure a tension-free anastomosis for left anterior descending coronary artery (LAD), left anterior descending diagonal coronary artery (LADD), and proximal right coronary artery (RCA) targets.

The pericardium was opened longitudinally over the intended target vessel and 10,000 units heparin was administered intravenously. Silicone elastomer retraction tapes (Quest Medical, Dallas, Tex) were passed around the native coronary artery proximal and distal to the site of intended grafting. Heavily diseased coronary targets were not occluded distally to prevent luminal plaque fracture. One to three 5minute cycles of ischemic preconditioning were performed as required to confirm stable hemodynamics.

An arteriotomy was fashioned in the target vessel and the conduit was prepared for grafting. Probing of the distal target vessel was avoided because this may result in vessel wall dissection or disruption of plaque when performed on a nonarrested heart. The arteriotomy site was stabilized with a handheld right-angle clamp with rubber bolsters. The conduit was anastomosed end to side in an antegrade fashion with a 7-0 polypropylene single parachute suture technique. Intraoperative graft flow was measured after completion of the anastomosis with a transit-time ultrasonographic flow probe (Transonic Systems, Inc, Ithaca, NY) to assist in detection of technical problems with the anastomosis before closure. After completion of the anastomosis the ITA pedicle was secured to the epicardium to ensure proper orientation. A small suction drain (Hemovac; Zimmer Patient Care Division, Dover, Ohio) without underwater seal was placed across the open pericardium and into the pleural space. The fourth costal cartilage was secured to the sternum with a single sternal wire, and a lateral intercostal block was placed with $0.5 \%$ bupivacaine hydrochloride (INN: bupivacaine) with epinephrine. The muscle and soft tissue were closed in layers and the drain was secured to the skin.

Patient follow-up. Routine systematic serial cardiac 
Table II. Operative conduit and target vessel selection

\begin{tabular}{lclr}
\hline Procedure and conduit & No. & Target vessel & No. \\
\hline Primary grafting & & & \\
LITA & 129 & LAD & 128 \\
& & LADD & 1 \\
Right ITA & 7 & RCA & 6 \\
& & LAD & 1 \\
Reoperative grafting & & & 13 \\
LITA & 19 & LAD & 1 \\
& & LAD & 5 \\
& & Existing saphenous & \\
Right ITA & 1 & RCin graft & 1 \\
Sequential grafting & & & \\
$\quad$ LITA & 2 & LADD, LAD & 2 \\
Bilateral grafting & & LAD & 4 \\
LITA & 4 & RCA & 4 \\
Right ITA & 4 & &
\end{tabular}

enzyme analyses were performed at 1 hour, 8 hours, and 16 hours after the operation in all cases, and additional analyses were performed as indicated. Patients were followed up prospectively after the operation with clinic visits at 2 weeks of follow-up, at 3 months of follow-up, and then annually. Transcutaneous Doppler velocimetric evaluation was performed at 2 weeks, 3 months, and 1 year to assess graft patency. Exercise thallium stress testing was performed at 3 months to evaluate improvement in myocardial perfusion in the grafted distribution. Coronary angiography was performed selectively for persistent or recurrent anginal symptoms, for failure to visualize the graft on subsequent outpatient Doppler velocimetric evaluation, or for a significant persistent ischemic defect on postoperative thallium stress testing.

\section{Results}

One hundred sixty-two patients underwent MIDCAB grafting with ITA during a 35-month period from August 1994 to July 1997. Mean length of follow-up was 12 months (range 0 to 31 months); 18 patients became unavailable for clinical follow-up at varying intervals. Survival and reintervention statuses are known for all patients. Operative procedural data according to conduit and target vessel selections are summarized in Table II.

Mortality. Eight patients (4.9\%) died within 30 days after the operation; 3 (1.9\%) died of cardiac causes. Seven additional patients $(4.3 \%)$ had late deaths at periods ranging from 2 to 21 months after the operation; $2(1.2 \%)$ died of cardiac causes. Kaplan-Meier analysis values for patient survival were 92\% (95\% confidence interval [CI] 87\%-95\%) at 12 months and 83\% (95\% CI 67\%-91\%) at 24 months (Fig 1). Mortality data are summarized in Table III.
Table III. Deaths

\begin{tabular}{|c|c|c|c|}
\hline No. & Age $(y)$ & Interval & Cause of death \\
\hline \multicolumn{4}{|c|}{$\begin{array}{l}\text { Early cardiac death } \\
\text { (<30 d after } \\
\text { operation })\end{array}$} \\
\hline 1 & 89 & Intraoperative & Cardiac failure \\
\hline 2 & 81 & $9 \mathrm{~d}$ & $\begin{array}{r}\text { Myocardial } \\
\text { infarction }\end{array}$ \\
\hline 3 & 71 & $24 \mathrm{~d}$ & $\begin{array}{r}\text { Myocardial } \\
\text { infarction }\end{array}$ \\
\hline \multicolumn{4}{|c|}{$\begin{array}{l}\text { Early noncardiac death } \\
(<30 \mathrm{~d} \text { after } \\
\text { operation })\end{array}$} \\
\hline 4 & 75 & $2 \mathrm{~h}$ & Aortic rupture \\
\hline 5 & 77 & $15 \mathrm{~d}$ & Respiratory failure \\
\hline 6 & 68 & $17 \mathrm{~d}$ & Sepsis \\
\hline 7 & 68 & $19 \mathrm{~d}$ & $\begin{array}{l}\text { Cerebrovascular } \\
\text { accident }\end{array}$ \\
\hline 8 & 70 & $27 \mathrm{~d}$ & Pulmonary embolus \\
\hline \multicolumn{4}{|c|}{$\begin{array}{l}\text { Late death } \\
\text { ( } \geq 30 \mathrm{~d} \text { after } \\
\text { operation) }\end{array}$} \\
\hline 9 & 58 & $2 \mathrm{mo}$ & Arrhythmia \\
\hline 10 & 45 & $3 \mathrm{mo}$ & Cardiac failure \\
\hline 11 & 86 & $2 \mathrm{mo}$ & Unknown \\
\hline 12 & 70 & $8 \mathrm{mo}$ & Unknown \\
\hline 13 & 87 & $16 \mathrm{mo}$ & Unknown \\
\hline 14 & 72 & $18 \mathrm{mo}$ & Unknown \\
\hline 15 & 64 & $21 \mathrm{mo}$ & $\begin{array}{l}\text { Cerebrovascular } \\
\text { accident }\end{array}$ \\
\hline
\end{tabular}

Morbidity. Seven patients (4.3\%) had myocardial infarction, defined as a creatine kinase MB isoenzyme value greater than $50 \mathrm{IU}$ on any 2 postoperative measurements. Four patients had undergone primary MID$\mathrm{CAB}$ grafting and 3 patients had undergone reoperative MIDCAB grafting. Two of the 7 patients who sustained myocardial infarction subsequently died. One older patient who underwent reoperative MIDCAB grafting had an intraoperative myocardial infarction, presumably from graft embolization during the initial dissection. An intra-aortic balloon pump was placed, but the patient subsequently died on postoperative day 9 . The second patient had a postinfarction ventricular septal defect develop as a result of graft occlusion; despite operative repair this patient died on postoperative day 24 .

Twenty-two (13.6\%) patients had atrial fibrillation or supraventricular tachycardia develop during the postoperative period; 20 of the episodes occurred before discharge. Three $(1.9 \%)$ patients had stroke or other significant neurologic impairment. The first patient died 2 weeks after the operation, after development of a stroke during hospitalization for pneumonia at another institution. The second patient had left-sided weak- 


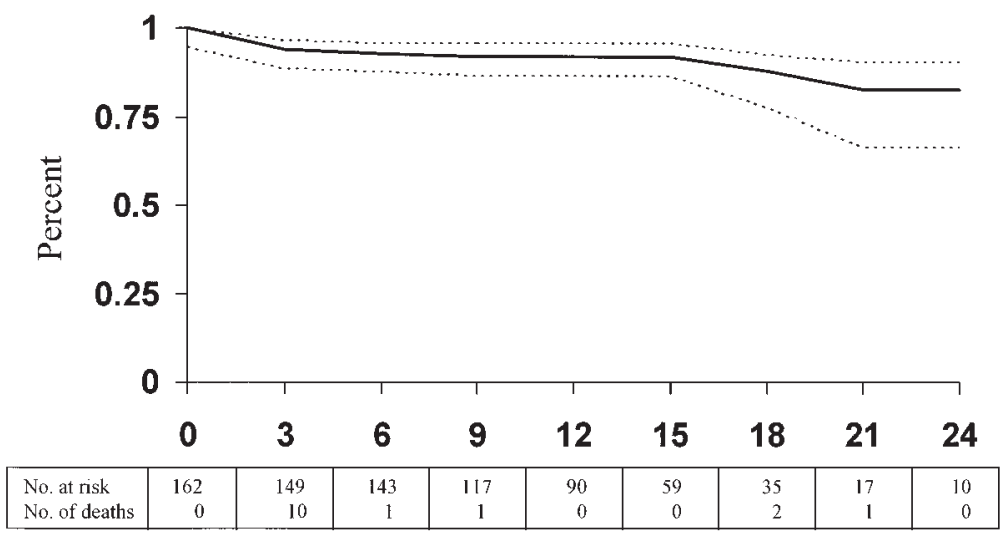

Survival in months

Fig 1. Kaplan-Meier curve (solid line) for patient survival after ITA MIDCAB grafting. Broken lines represent $95 \%$ CI. Freedom from death values were $92 \%$ (95\% CI 87\%-95\%) at 12 months $83 \%$ (95\% CI 67\%-91\%) at 24 months.

ness several hours after discharge on the sixth postoperative day; this subsequently resolved. The third patient had symptoms consistent with transient cerebral ischemia on postoperative day 2 ; these symptoms resolved spontaneously.

Twenty-four patients (14.8\%) had inflammation or infection develop at the primary operative site. Six patients $(3.7 \%)$ had infections that necessitated operative débridement or revision of the incision. The remaining 18 patients with infections had inflammation or minor infections treated in the clinic with dressings or antibiotics. Most of these wound complications occurred in patients with submammary incisions. No patient had sternal infection or evidence of mediastinitis.

Three patients (1.9\%) required surgical reexploration. The first patient was returned to the operating room twice on the day of operation for bleeding; no site was found at either exploration. A second patient had acute graft occlusion immediately after the operation; reexploration was performed and the graft was revised. This patient sustained a postinfarction ventricular septal defect despite these measures, as described previously. A third patient had early postoperative electrocardiographic changes that were treated urgently with angioplasty of the native LAD. Reexploration the next morning revealed graft compression by the migrated lateral edge of the pericardium; release of this impingement restored normal graft flow.

Fifteen patients $(9.3 \%)$ required thoracentesis, chest tube placement, or both for pleural effusion after MID$\mathrm{CAB}$ grafting. Eight of the patients required this intervention before their discharge from the hospital and in
7 patients the pleural effusion necessitating thoracocentesis developed after their discharge.

Conversion to conventional bypass grafting. Ten patients $(6.2 \%)$ required conversion to conventional coronary bypass grafting. Seven of these patients had primary left ITA (LITA) to LAD grafting, 1 patient had reoperative LITA to LAD grafting, 1 patient had primary bilateral ITA grafting to the LAD and RCA, and 1 patient had primary right ITA to RCA grafting. Indications for conversion to conventional coronary artery bypass with cardiopulmonary bypass included hemodynamic instability in 4 cases, arrhythmia in 2 cases, inadequate exposure in 2 cases, ITA dissection in 1 case, and excessive bleeding in 1 case.

Five patients (3.1\%) underwent full sternotomy without cardiopulmonary bypass. Three of these patients underwent primary ITA grafting and 2 underwent reoperative grafting. Two of the patients required a full sternotomy because of inadequate exposure for grafting through the MIDCAB incision. One patient required a full sternotomy during reexploration for bleeding.

Length of stay. Mean overall postoperative length of stay for all patients was 2.5 days (range 0-27 days). Mean overall length of stay for all patients except those who died while in the hospital was 2.2 days (range 112 days).

Recatheterization and reintervention. Twentyseven patients $(16.7 \%)$ underwent postoperative recatheterization for symptoms, for inadequate graft flow according to Doppler velocimetric evaluation, for persistent defect according to thallium stress testing, or during a planned procedure on another vessel (Table IV). Fourteen patients had normal grafts and 2 had pro- 
Table IV. Recatheterization and reintervention

\begin{tabular}{|c|c|c|c|c|}
\hline Patient & $\begin{array}{c}\text { Postoperative } \\
\text { interval }\end{array}$ & Operation & Findings & Result \\
\hline \multicolumn{5}{|c|}{ Normal grafts } \\
\hline 16 & $1 \mathrm{~d}$ & LITA to LAD & Normal & \\
\hline 13 & $1 \mathrm{wk}$ & LITA to LAD & Normal & \\
\hline 17 & $2 \mathrm{wk}$ & LITA to LAD & Normal & \\
\hline 18 & $2 \mathrm{mo}$ & LITA to LAD & Normal & \\
\hline 19 & $2 \mathrm{mo}$ & LITA to LAD & Normal & \\
\hline 20 & $2 \mathrm{mo}$ & LITA to LAD & Normal & \\
\hline 12 & $3 \mathrm{mo}$ & LITA to LAD & Normal & \\
\hline 21 & $4 \mathrm{mo}$ & LITA to LAD & Normal & \\
\hline 14 & $10 \mathrm{mo}$ & LITA to LAD & Normal & \\
\hline 22 & $11 \mathrm{mo}$ & LITA to LAD & Normal & \\
\hline 23 & $11 \mathrm{mo}$ & LITA to LAD & Normal & \\
\hline 24 & $12 \mathrm{mo}$ & LITA to LAD & Normal & \\
\hline 25 & $12 \mathrm{mo}$ & LITA to LAD & Normal & \\
\hline 26 & $12 \mathrm{mo}$ & LITA to LAD & Normal & \\
\hline \multicolumn{5}{|c|}{$\begin{array}{l}\text { Native vessel stenoses } \\
\text { (remote locations) }\end{array}$} \\
\hline 27 & $3 \mathrm{mo}$ & LITA to LAD & RCA stenosis & $\begin{array}{l}\text { Successful percutaneous transluminal coronary } \\
\text { angioplasty }\end{array}$ \\
\hline 28 & $8 \mathrm{mo}$ & LITA to LAD & Distal LAD stenosis & No attempt at dilation \\
\hline \multicolumn{5}{|c|}{ Graft occlusions } \\
\hline 3 & $2 \mathrm{~d}$ & LITA to LAD & Occluded & Unsuccessful attempt at dilation \\
\hline 9 & $2 \mathrm{wk}$ & LITA to LAD & Occluded & Unsuccessful attempt at dilation \\
\hline 29 & $5 \mathrm{wk}$ & LITA to LAD & Occluded & Unsuccessful attempt at dilation \\
\hline 30 & $13 \mathrm{mo}$ & LITA to LAD & Occluded & Unsuccessful attempt at dilation \\
\hline \multicolumn{5}{|c|}{ Graft stenoses } \\
\hline 31 & Day of operation & LITA to LAD & Graft stenosis & $\begin{array}{l}\text { Successful percutaneous transluminal coronary } \\
\text { angioplasty and stent }\end{array}$ \\
\hline 32 & $1 \mathrm{mo}$ & LITA to LAD & Graft stenosis & No attempt at dilation \\
\hline 33 & 4 mo & LITA to LAD & Graft stenosis & No attempt at dilation \\
\hline 34 & $18 \mathrm{mo}$ & LITA to LAD & Graft stenosis & $\begin{array}{l}\text { Successful percutaneous transluminal coronary } \\
\text { angioplasty and stent }\end{array}$ \\
\hline \multicolumn{5}{|c|}{ Anastomotic stenoses } \\
\hline 35 & $1 \mathrm{mo}$ & LITA to LAD & Anastomotic stenosis & $\begin{array}{l}\text { Successful percutaneous transluminal coronary } \\
\text { angioplasty }\end{array}$ \\
\hline 4 & $2 \mathrm{mo}$ & LITA to LAD & Anastomotic stenosis & $\begin{array}{l}\text { Successful percutaneous transluminal coronary } \\
\text { angioplasty }\end{array}$ \\
\hline 36 & $3 \mathrm{mo}$ & LITA to LAD & Anastomotic stenosis & $\begin{array}{l}\text { Successful percutaneous transluminal coronary } \\
\text { angioplasty }\end{array}$ \\
\hline
\end{tabular}

gression of native coronary vessel disease at other locations. Nine patients $(5.6 \%)$ required reintervention for stenotic or occluded grafts. Kaplan-Meier analysis values for freedom from reintervention were $95 \%(95 \%$ CI, 91\%-98\%) at 12 months and 92\% (95\% CI, 82\%$96 \%$ ) at 24 months (Fig 2).

Four patients (2.5\%) had occlusion of the ITA conduit. One patient was found to have graft occlusion on recatheterization 2 days after the operation; the graft was revised and subsequently reoccluded a second time. Attempts at percutaneous dilation were unsuccessful on 2 separate occasions. A second patient had a wound infection that bled after wound revision and compressed the graft; attempts at percutaneous dilation were unsuccessful. A third patient was found to have no diastolic augmentation in the graft according to Doppler velocimetric evaluation at 5 weeks after the operation. Recatheterization confirmed graft occlusion, and attempts at percutaneous dilation were unsuccessful. A fourth patient had recurrent chest pain 1 year after the operation. Recatheterization demonstrated graft occlusion, and attempts at percutaneous dilation were unsuccessful.

Four patients $(2.5 \%)$ had graft stenoses develop. One patient had graft impingement by the pericardial edge, as described previously. Two patients had non-flow- 


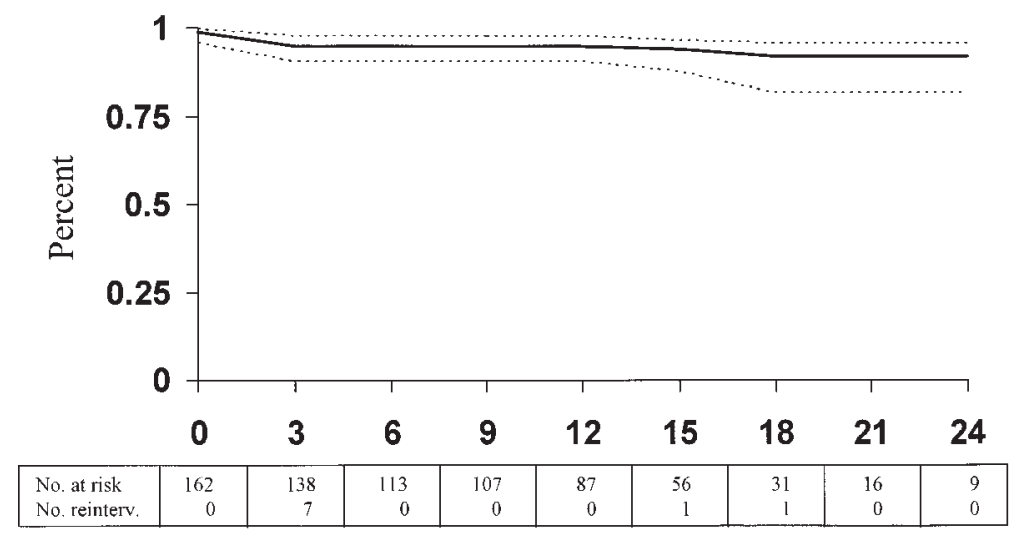

Follow-up in months

Fig 2. Kaplan-Meier curve (solid line) for reintervention after ITA MIDCAB grafting. Broken lines represent $95 \%$ CI. Freedom from reintervention values were $95 \%$ (95\% CI 91\%-98\%) at 12 months and $92 \%$ (95\% CI $82 \%$ $96 \%)$ at 24 months.

limiting narrowings in the graft that did not require reintervention. A fourth patient had a reversible ischemic defect according to follow-up thallium stress testing 18 months after the operation. Recatheterization showed stenosis of the ITA graft, and a stent was successfully placed. Three patients (1.9\%) had anastomotic stenoses; all stenoses occurred within 3 months after the operation and were successfully dilated with percutaneous methods.

Follow-up. Intraoperative graft flow assessed by transit-time ultrasonography averaged $23.8 \mathrm{~mL} / \mathrm{min}$ (range $1-70 \mathrm{~mL} / \mathrm{min}$ ). Postoperative transcutaneous Doppler velocimetric analyses of the ITA graft were performed in 138 cases $(85.2 \%)$. Three patients had evidence of decreased flow in the conduit, 2 at the 2 week examination and 1 at the 5-week examination. The former 2 patients were both free of symptoms, and recatheterization was not performed. The latter patient had graft occlusion on recatheterization, as described previously. Doppler velocimetric analyses were performed in 122 cases at 2 weeks of follow-up, in 109 cases at 3 months, and in 60 cases at 1 year. Three patients have had Doppler velocimetric evaluations at 2 years of follow-up; all have evidence of patent grafts.

Thallium stress testing was performed in 106 cases $(65.4 \%)$ at 3 months of follow-up. Nineteen patients were found to have a persistent reversible ischemic defect, although all grafts evaluated by Doppler velocimetric study demonstrated flow. Ten of these patients underwent recatheterization, 1 had graft occlusion, 2 had anastomotic stenoses, and 2 had native vessel stenoses, as described in detail previously.
One hundred forty-one (95.9\%) of 147 surviving patients were evaluated for symptoms during clinic visits at 2 weeks of follow-up, at 3 months of follow-up, and then annually. Of these, $6(4.1 \%)$ had persistent symptoms and $5(3.4 \%)$ required additional medical therapy to relieve their anginal symptoms. Antegrade flow of the ITA conduit was documented by Doppler velocimetry in 135 (97.8\%) of 138 patients studied. One hundred thirty-five (95.7\%) of 141 patients seen in the clinic had resolution of their symptoms either with or without additional medical therapy.

\section{Discussion}

Revascularization of the LAD with the LITA has become the standard of care in coronary artery bypass grafting. Several series with long-term follow-up have now documented the protective effects of the LITA with respect to saphenous vein grafting and other conduits. ${ }^{5-10}$ This knowledge was applied to MIDCAB procedures early in the development of minimally invasive techniques because the LITA lends itself well to this approach.

This series of patients represents the initial experience with MIDCAB grafting performed with early exposure techniques and without currently available automated mechanical stabilization. In addition, a selective approach for recatheterization was employed, which is an inherent weakness of this report. Nevertheless, this experience is comparable to other published reports of MIDCAB grafting with the ITA conduit. Calafiore and associates ${ }^{3}$ have reported on the largest series to date $(n=155$ patients) of use of the 
LITA to graft the LAD, with excellent mortality and patency rates, and other, smaller series have also demonstrated encouraging early results. ${ }^{1,2,4,5}$ In this series most (7/9) graft stenoses or occlusions necessitating reintervention occurred within 3 months after the operation. The 3-year follow-up suggests that these conduits behave as would be expected after successful graft placement with conventional coronary artery bypass techniques.

MIDCAB grafting with the ITA has been demonstrated in some series to carry low attendant early mortality and perioperative infarction rates. In this set of patients all early deaths were restricted to patients older than 70 years, and 3 of the 8 deaths were of patients who underwent reoperation. This suggests that MIDCAB grafting with the ITA can be most effectively employed in young, otherwise healthy patients with single-vessel disease. In contrast, elderly patients with significant comorbidities and patients undergoing reoperative procedures, who are at higher risk with conventional coronary artery bypass, did not have a reduced risk with MIDCAB in this series. Earlier studies among patients undergoing conventional coronary artery bypass procedures examined the role of ITA grafting in elderly patients and did not associate the use of the ITA graft with an increased mortality rate among these patients. ${ }^{8,10}$ However, a recent study by $\mathrm{He}$ and associates ${ }^{11}$ of patients undergoing conventional coronary artery bypass grafting demonstrated that use of the right ITA and reoperation were among the risk factors associated with increased early mortality rates among elderly patients receiving ITA grafts. It is unclear from this series why the MIDCAB approach did not reduce the operative risk in this subset of patients.

The MIDCAB approach was effective in reducing some of the common postoperative complications that are associated with conventional coronary artery bypass grafting. There was a low rate of supraventricular arrhythmia (13.6\%), with most (20/22) cases occurring before discharge. There was a small but important percentage of patients $(9.3 \%)$ who required thoracentesis, chest tube placement, or both for pleural effusion. Nearly half of these patients had their effusion after discharge from the hospital or required multiple thoracocenteses for recurrent effusion. Both complications underscore the importance of close follow-up because arrhythmia or effusion may develop after the patient has been discharged.

MIDCAB grafting with the ITA did not substantially reduce the incidence of central nervous system events $(1.9 \%)$, as indicated by the 3 patients who had neurologic injury. These injuries occurred despite the avoid- ance of manipulation of the great vessels and cardiopulmonary bypass. The causes of these events are unclear because none occurred within 48 hours after the operation and none were readily attributed to perioperative phenomena.

MIDCAB grafting was associated with a high rate of wound inflammation or infection $(14.8 \%)$ in this series of patients, although most of these complications were minor. Most of these infections were associated with the submammary incision. This association prompted modification to place the incision $1 \mathrm{~cm}$ above the inframammary fold and to avoid its use in patients with diabetes and those with particularly pendulous breast tissue. Importantly, none of these infections resulted in sternal infection or mediastinitis, and most patients required only simple drainage and antibiotics.

Experience with right ITA and bilateral ITA grafting is accumulating in the MIDCAB setting and further extends the range of the minimally invasive approach. Right ITA grafting in conventional coronary artery bypass has had excellent patency rates when grafted to the LAD but is also useful in patients without venous conduits and in isolated proximal RCA disease. ${ }^{12,13}$ Combined bilateral right and LITA grafting in conventional coronary artery bypass procedures has been shown to carry good long-term survival and improvement in functional status; it is unclear whether bilateral ITA grafting increases surgical risk or infection rates among these patients. ${ }^{14-17}$ Four patients in this series underwent bilateral ITA grafting to the LAD and RCA. No patient had wound infection, and 1 patient died 3 weeks after the MIDCAB procedure of a pulmonary embolus after a hip replacement operation. These anecdotal results confirm the case report by Watanabe and associates $^{18}$ and suggest further investigation into this technique.

In conclusion, MIDCAB grafting with the ITA is a versatile operation that results in excellent relief of patients' symptoms. Early mortality rates were not as low as anticipated, however, particularly in the subset of patients considered to be at higher risk when undergoing conventional coronary artery bypass grafting. The ITA can be used for isolated grafting of anterior coronary vessels or for more extensive grafting procedures, including sequential grafting and bilateral ITA grafting. MIDCAB grafting with the ITA reduces the incidence of postoperative supraventricular arrhythmia and reduces postoperative length of stay, allowing patients to return to normal activity much sooner than does conventional coronary bypass grafting. Long-term followup continues to confirm the durability of ITA grafts placed with MIDCAB techniques. 


\section{REFERENCES}

1. Acuff TE, Landreneau RJ, Griffith BP, Mack MJ. Minimally invasive coronary artery bypass grafting. Ann Thorac Surg 1996; 61:135-7.

2. Benetti FJ, Ballester C. Use of thoracoscopy and a minimal thoracotomy, in mammary-coronary bypass to left anterior descending artery, without extracorporeal circulation. J Cardiovasc Surg 1995;36:159-61.

3. Calafiore AM, Di Giammarco G, Teodori G, Bosco G, D'Annunzio E, Barsotti A, et al. Left anterior descending coronary artery grafting via left anterior small thoracotomy without cardiopulmonary bypass. Ann Thorac Surg 1996;61:1658-65.

4. Robinson M, Gross D, Zeman W, Stedje-Larsen E. Minimally invasive coronary artery bypass grafting: a new method using an anterior mediastinotomy. J Card Surg 1995;10:529-36.

5. Gill IS, FitzGibbon GM, Higginson LA, Valji A, Keon WJ. Minimally invasive coronary artery bypass: a series with early qualitative angiographic follow-up. Ann Thorac Surg 1997;64: 710-4.

6. Barner HB, Barnett MG. Fifteen- to twenty-one-year angiographic assessment of internal thoracic artery as a bypass conduit. Ann Thorac Surg 1994;57:1526-8.

7. Boylan MJ, Lytle BW, Loop FD, Taylor PC, Borsh JA, Goormastic M, et al. Surgical treatment of isolated left anterior descending coronary stenosis. J Thorac Cardiovasc Surg 1994; 107:657-62.

8. Gardner TJ, Greene PS, Rykiel MF, Baumgartner WA, Cameron DE, Casale AS, et al. Routine use of the left internal mammary artery graft in the elderly. Ann Thorac Surg 1990;49:188-94.

9. Loop FD, Lytle BW, Cosgrove DM, Stewart RW, Goormastic M, Williams GW, et al. Influence of the internal-mammary-artery graft on 10-year survival and other cardiac events. N Engl J Med 1986;314:1-6.
10. Wareing TH, Saffitz JE, Kouchoukos NT. Use of single internal mammary artery grafts in older patients. Circulation 1990;82: IV224-8.

11. He GW, Acuff TE, Ryan WH, Bowman RT, Douthit MB, Mack MJ. Determinants of operative mortality in elderly patients undergoing coronary artery bypass grafting: emphasis on the influence of internal mammary artery grafting on mortality and morbidity. J Thorac Cardiovasc Surg 1994;108:73-81.

12. Chow MS, Sim E, Orszulak TA, Schaff HV. Patency of internal thoracic artery grafts: comparison of right versus left and importance of vessel grafted. Circulation 1994;90:II129-32.

13. Ramström J, Lund O, Cadavid E, Oxelbark S, Thuren JB, Henze AC. Right internal mammary artery for myocardial revascularization: early results and indications. Ann Thorac Surg 1993; 55:1485-91.

14. Galbut DL, Traad EA, Dorman MJ, DeWitt PL, Larsen PB, Kurlansky PA, et al. Bilateral internal mammary artery grafts in reoperative and primary coronary bypass surgery. Ann Thorac Surg 1990;49:195-201.

15. Galbut DL, Traad EA, Dorman MJ, DeWitt PL, Larsen PB, Kurlansky PA, et al. Seventeen-year experience with bilateral internal mammary artery grafts. Ann Thorac Surg 1990;49:195201.

16. Kouchoukos NT, Wareing TH, Murphy SF, Pelate C, Marshall WG Jr. Risks of bilateral internal mammary artery bypass grafting. Ann Thorac Surg 1990;49:210-9.

17. Cosgrove DM, Lytle BW, Loop FD, Taylor PC, Stewart RW, Gill $\mathrm{CC}$, et al. Does bilateral internal mammary artery grafting increase surgical risk? J Thorac Cardiovasc Surg 1988;95:850-6.

18. Watanabe G, Misaki T, Kotoh K, Abe Y, Yamashita A, Ueyama K. Bilateral minimally invasive direct coronary artery bypass grafting with the use of two arterial grafts. J Thorac Cardiovasc Surg 1997;113:949-51. 